\title{
A national survey exploring UK trainees' perceptions, core training experience, and decisions to pursue advanced training in breast radiology
}

DOI:

10.1016/j.crad.2017.06.013

\section{Document Version}

Accepted author manuscript

Link to publication record in Manchester Research Explorer

Citation for published version (APA):

Lowes, S., Bydder, M., \& Sinnatamby, R. (2017). A national survey exploring UK trainees' perceptions, core training experience, and decisions to pursue advanced training in breast radiology. Clinical Radiology. https://doi.org/10.1016/j.crad.2017.06.013

\section{Published in:}

Clinical Radiology

\section{Citing this paper}

Please note that where the full-text provided on Manchester Research Explorer is the Author Accepted Manuscript or Proof version this may differ from the final Published version. If citing, it is advised that you check and use the publisher's definitive version.

\section{General rights}

Copyright and moral rights for the publications made accessible in the Research Explorer are retained by the authors and/or other copyright owners and it is a condition of accessing publications that users recognise and abide by the legal requirements associated with these rights.

\section{Takedown policy}

If you believe that this document breaches copyright please refer to the University of Manchester's Takedown Procedures [http://man.ac.uk/04Y6Bo] or contact uml.scholarlycommunications@manchester.ac.uk providing relevant details, so we can investigate your claim.

\section{OPEN ACCESS}




\section{Accepted Manuscript}

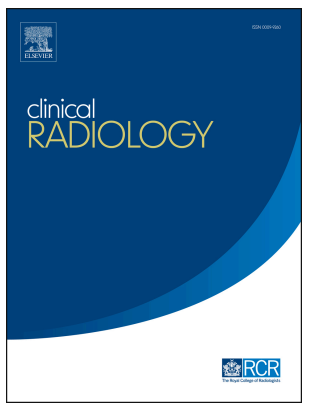

A national survey exploring UK trainees' perceptions, core training experience, and decisions to pursue advanced training in breast radiology

S. Lowes, M. Bydder, R. Sinnatamby

PII:

S0009-9260(17)30241-6

DOI:

10.1016/j.crad.2017.06.013

Reference: $\quad$ YCRAD 4647

To appear in: Clinical Radiology

Received Date: 6 March 2017

Revised Date: 30 May 2017

Accepted Date: 13 June 2017

Please cite this article as: Lowes S, Bydder M, Sinnatamby R, A national survey exploring UK trainees' perceptions, core training experience, and decisions to pursue advanced training in breast radiology, Clinical Radiology (2017), doi: 10.1016/j.crad.2017.06.013.

This is a PDF file of an unedited manuscript that has been accepted for publication. As a service to our customers we are providing this early version of the manuscript. The manuscript will undergo copyediting, typesetting, and review of the resulting proof before it is published in its final form. Please note that during the production process errors may be discovered which could affect the content, and all legal disclaimers that apply to the journal pertain. 
[for E-Pub ONLY]

A national survey exploring UK trainees' perceptions, core training experience, and decisions to pursue advanced training in breast radiology

S. Lowes ${ }^{\mathrm{a}, \star}$, M. Bydder ${ }^{\mathrm{b}}$, R. Sinnatamby ${ }^{\mathrm{c}}$

${ }^{a}$ Department of Radiology, Queen Elizabeth Hospital, Gateshead, UK

${ }^{b}$ Department of Radiology, Nightingale Centre \& Genesis Prevention Centre, University Hospital of South Manchester, Manchester, UK

${ }^{c}$ Department of Radiology, Cambridge Breast Unit, Cambridge University Hospitals, Cambridge, UK

*Guarantor and correspondent: S. Lowes, Department of Radiology, Queen Elizabeth Hospital, Gateshead, UK. Tel.: ???

E-mail address: simon.lowes@doctors.org.uk

\section{ABSTRACT}

AIM: To investigate UK radiology trainees' perceptions of breast radiology and the factors that influenced their decision whether or not to choose breast radiology as an area of special interest.

MATERIALS \& METHODS: An online survey was compiled and distributed to all UK specialty trainees in clinical radiology via the Royal College of Radiologists Junior Radiologists' Forum (JRF) regional representatives.

RESULTS: There were 275 respondents, representing $22 \%$ of all UK radiology trainees. Responses were received from all regions. A significant factor identified in influencing whether or not trainees decide to pursue advanced training in breast 
radiology is the timing and quality of their initial core training experience. Specific positive aspects of breast radiology that were repeatedly identified included the high level of patient contact and frequent use of interventional procedures. Recurring negative aspects of breast radiology included isolation from general radiology and finding the subject matter boring.

CONCLUSION: Breast radiology faces a significant workforce shortfall that is predicted to worsen in the coming years. There has never been a greater need to recruit specialty trainees into this field, and action is urgently needed to help ensure the sustainability of breast services and drive further improvements to patient care. The findings from this survey should be regarded as a challenge to all breast radiologists to engage with trainees from an early stage in their training and to enthuse them with the many positive aspects of a career in breast radiology.

\section{INTRODUCTION}

Demand for the services of breast radiologists has never been higher. Breast cancer not only remains the most common cancer in the $\mathrm{UK}^{1}{ }^{1}$ but the annual number of newly diagnosed female breast cancers has risen continually for the last 20 years. $^{2}$ With extension of the age range for the NHS Breast Screening Programme, and the requirement for all women presenting with breast symptoms to be assessed within 2 weeks, ${ }^{3}$ the workload of the breast radiologist continues to increase. Greater use of more complex imaging such as breast magnetic resonance imaging (MRI) for surgical treatment planning, high-risk cancer screening, and assessing response to neoadjuvant chemotherapy places further demand on breast radiologists' time.

A critical problem in meeting this demand is the recognised shortage of breast radiologists in the UK, a situation that is expected to worsen significantly over the coming years. Although breast radiology is the largest area of special interest within 
general radiology, it faces the greatest workforce deficits. ${ }^{4}$ A survey of NHS Breast Screening Programme units and radiology departments carried out in $2015^{5}$ confirmed significant understaffing issues, showing that $25 \%$ of NHS Breast Screening Programme units operate with just one or two consultant radiologists with no cover for sickness or absence. There were 60 vacant consultant breast radiologist posts across the UK, representing around $13 \%$ of all substantive posts. Less than half of these were expected to be filled within the following 12 months. Moreover, $21 \%$ of breast radiologists are expected to retire by 2020 , increasing to $38 \%$ by 2025 , and $53 \%$ by 2030 , which will have a severe impact on breast cancer screening and diagnosis unless these positions are filled.

These problems are further compounded by the recognition that too few breast radiologists are being trained. ${ }^{5}$ The standard clinical radiology specialty training programme within the UK comprises 3 years of core radiology training (ST1-3) followed by 2 years (ST4-5) of advanced (special interest) radiology training, allowing trainees to develop higher competences in a specific area(s). ${ }^{6}$ The exception to this is training in interventional radiology, which is currently the only formally recognised subspecialty within radiology, lasting for 6 years (ST6) and leading to a separate CCT. During ST1-3, all trainees are required to gain experience and basic competences across the core components of radiology, including breast radiology. Summative assessment of the core curriculum in breast radiology occurs in both parts $A$ and $B$ of the final Fellowship of the Royal College of Radiologists (FRCR) exam. During ST4-5, trainees spend dedicated time in their chosen area(s) of special interest and develop higher competences in preparation for work as a consultant.

In order to inform potential improvements in recruitment of trainees to breast radiology at ST4-5 level, the present study was undertaken to survey all UK radiology trainees regarding their perceptions of breast radiology and the factors that 
influenced their decision whether or not to choose breast radiology as an area of special interest.

\section{MATERIALS AND METHODS}

The survey was compiled on SurveyMonkey (www.surveymonkey.net) and distributed to UK specialty trainees in clinical radiology via the Royal College of Radiologists Junior Radiologists' Forum (JRF) regional representatives. There were 35 questions in total (Electronic Supplementary Material Appendix S1), but not all were applicable to each respondent. "Page logic" was applied, automatically directing respondents to the most appropriate next question based on their response to the previous question. Before distribution the survey was approved by the British Society of Breast Radiology (BSBR) executive committee and was distributed under the auspices of the BSBR. The survey was opened in February 2016 and remained active for 6 weeks. An initial pilot was distributed to trainees within the Northern School of Radiology to identify and correct any errors.

The survey responses were anonymised; however, participation in the survey was incentivised by offering three prizes of high street vouchers to respondents who elected to leave their email addresses. Email addresses were used only for the purpose of contacting the prize winners. The three winners were drawn at random by two members of the BSBR executive committee once the survey had closed. Winners were notified and the prizes allocated.

\section{RESULTS}

Response rate

Overall 275 trainees completed the survey. In March 2016, during the time the survey was "live", there were a total of 1,270 clinical radiology trainees in the UK 
(figure obtained from an enquiry to the Royal College of Radiologists), giving a response rate of $22 \%$.

Demographics and working patterns

There was at least one response from each training region in the UK (Table 1). Overall, years ST1 through to ST5 were well represented (Fig. 1). As expected, far fewer responses were obtained from those in ST6 as only a small proportion of radiology training programmes extend to ST6 level. There was one response from a post-CCT trainee ("Other", Fig. 1). Table 2 shows the gender and age distribution of respondents.

Eighty-eight percent were currently in full-time training (FTT), with the remaining $12 \%$ in less than full-time training (LTFTT). Of those in FTT, 78.4\% planned to remain in FTT, $6.6 \%$ planned to switch to LTFTT in the future, and $14.9 \%$ were undecided. Of those currently in FTT, $55.8 \%$ said they were planning on working full-time as a consultant, $9.5 \%$ were planning on working less than full-time, and $34.7 \%$ were undecided. Of those currently in LTFTT, 9.1\% said they were planning on working full-time as a consultant, $33.3 \%$ planning on working less than full-time, and $57.6 \%$ undecided.

Choice of special interest training

When asked about their choice of special interest, 272 of the 275 respondents answered. Thirty-five (12.9\%) had chosen breast radiology, 16 of whom were currently undertaking special interest training in breast radiology, the other 19 having chosen it but not yet commenced their advanced training. Of the remaining respondents, $123(45.2 \%)$ had chosen another area of special interest, and 114 (41.9\%) had not yet made their decision. 


\section{Those who chose breast radiology as a special interest}

Of the 35 respondents who had chosen breast radiology, $80 \%$ planned to combine it with general radiology (or another area of special interest) as a consultant, and $20 \%$ planned to work solely in breast radiology. The respondents were asked in more detail about when and why they chose breast radiology. Just over half (54.3\%) made the decision to train in breast radiology during their core breast radiology rotation, $20 \%$ after their core breast radiology rotation, $17.1 \%$ before their rotation but after starting radiology, and the remaining $8.6 \%$ knew they wanted to do breast radiology by the time they entered ST1. Fig. 2 shows the various reasons why trainees might have chosen breast radiology. These were selected from a list of pre-prepared options, and respondents were able to select multiple reasons. A free text option was also available under "Other"; one respondent selected this stating they had an "Interest in doing women's imaging (breast and gynae[cological] radiology)". Overall the strongest reasons for choosing breast radiology related to the job itself, with the top three reasons being: "Interested in the subject", "Good level of patient contact", and "Positive experience during core rotation". Interestingly, some of the less popular reasons were those that may have been perceived to be positive aspects of the pattern of working, for example, opportunities for flexible or less than full-time working, no or limited on-call work, and opportunities for private practice or extra paid sessions.

When asked how they felt about their decision to choose breast radiology, all respondents were either very happy or satisfied with their choice (excluding those who had not yet commenced their advanced breast radiology training and were unable to comment; Fig. 3). 


\section{Those who chose a special interest other than breast radiology}

The 123 respondents who had chosen a different area of special interest were given a subset of questions to try and ascertain how likely they would have been to have chosen breast radiology instead of their chosen special interest. They were asked to choose one of three statements that best matched their situation (120 of the 123 respondents answered the questions): $48.3 \%$ said that breast radiology was definitely not a special interest they had wanted to pursue, $41.7 \%$ said that breast radiology was not an area of special interest they seriously considered or had no strong feelings regarding it, and the remaining $10 \%$ answered that although they had chosen another special interest in the end, breast radiology had been high on their list of options.

Respondents were then asked to select from a list one or more factors about breast radiology that influenced their decision not to choose it. These are summarised in Fig. 4. The top 3 reasons were "Not interested in subject", "Isolated from main radiology", and "Find it boring". Factors such as a negative attitude about the specialty from breast radiologists, negative views by other (non-breast) radiologists or the media, or perceived threats to the breast radiology as a specialist area, accounted for only a small proportion of responses (Fig. 4). Twenty-seven respondents (22.5\%) also selected "Other" and provided free-text responses. Where possible, these free-text responses have been grouped for clarity: "Monotonous/repetitive/boring" ( $n=8)$, "Just preferred another specialty" $(n=6)$, "Difficult to combine with another subspecialty/too specialised" $(n=4)$, "Don't agree with/dislike screening programme" $(n=2)$, "Too busy" $(n=2)$, "Not fast enough pace" $(n=1)$, "Female dominated subspecialty" $(n=1)$, "Lack of acute patients" $(n=1)$, "Too much clinic time" $(n=1)$, "Very protocol driven" $(n=1)$. Almost all respondents said 
they had no regrets about not choosing breast radiology, with only $1.7 \%$ (two respondents) reporting that they did regret not choosing it.

Those who had not yet made their decision regarding area of special interest

The 114 respondents who were undecided regarding their area of special interest were asked about whether they had considered, or were considering, breast radiology. Respondents were asked to choose one of five options: $21.2 \%$ said they were considering breast radiology as one of their possible areas of special interest (with or without another area of special interest); $27.4 \%$ had given some consideration to special interest choices but had not considered breast radiology as an option; $18.6 \%$ said they had considered breast radiology as a possible option but were unlikely to pursue it; $13.3 \%$ said breast radiology was definitely not a special interest area they wanted to pursue; and $19.5 \%$ had not yet given any real consideration to possible special interest choices.

Based on their current perceptions and experiences of breast radiology, respondents were then asked to select reasons they may have for either choosing or not choosing to pursue it in their higher training. These are summarised in Figs. 5 and 6, respectively. Regarding the positive factors about breast radiology, the top three reasons related directly to the job: "Good level of patient contact", "Lots of procedures/intervention", and "Enjoy working within multidisciplinary team" (Fig. 5). The subsequent five reasons were all factors relating to job opportunities and working patterns: "Good job opportunities", "Offers good work/life balance", "No or limited on-call", "Flexible working hours", and "Opportunity for less than full-time working", indicating that these are also seen as important. Two respondents also entered free-text reasons under "Other", citing "Excellent teamwork and positive work ethos" and "High demand" as positive factors. Regarding the possible reasons for not 
choosing breast radiology, the top three reasons selected were "Isolated from main radiology", "Not interested in the subject", and "Concerned about the potential for litigation" (Fig. 6). Negative profiles of the speciality (by other radiologists or the media), or perceived threats to the specialty, seemed less important (Fig. 6). Fifteen respondents also entered free-text reasons under "Other". Notable reasons (paraphrased for brevity) were "Limited variety/limited pathology" ( $n=3)$, "Limited evidence/detrimental effect of breast screening" $(n=2)$, "Easier role for females/negative attitude by others towards men becoming breast radiologists" ( $n=2)$, "Skills mix too prevalent" $(n=1)$.

Core training experience in breast radiology

Trainees were asked whether a core breast radiology rotation was included in their training programme. $87.3 \%$ replied "Yes", 6.3\% "No", and 6.3\% were unsure. In most instances, core breast rotations take place at variable times throughout years ST1-3, though those that take place in a fixed year most commonly take place in ST2 (Fig. 7a). Most rotations last for 3 months (Fig. 7b) and most rotations comprise three or four breast sessions per week (Fig. 7c).

Sixty-six percent of respondents had completed their core breast rotation at the time of the survey. This equated to 151 respondents out of 228 (47 managed to skip the question). Of these, $55 \%$ said they enjoyed the rotation, $40 \%$ neither enjoyed nor disliked it, and only $5 \%$ said they disliked it. Table 3 shows the factors contributing to trainees' enjoyment of their core breast rotation. Being made to feel welcome by staff in the department and having good support from the consultants were the commonest reasons given. Also ranking highly was that breast radiology involves lots of procedures and that trainees are encouraged to get involved, with patient contact being next highest on the list. Two respondents also selected "Other", citing 
that they "Felt part of a team" and that breast radiology is "Easy compared to other subspecialties". Table 4 lists the factors contributing to trainees' dislike of their core breast rotation. Forty percent of respondents felt there was nothing they disliked about the rotation. Ranked next highest was that trainees found the subject matter boring. Also featuring highly were the feelings that trainees were not given many opportunities to carry out procedures or were not given enough exposure to the different techniques used. Twenty-two respondents also made free-text comments under "Other". The most relevant comments have been selected and where appropriate paraphrased, with numbers of respondents in brackets: "Too much breast radiology/waste of time/repetitive" $(n=5)$, "Not enough exposure to breast radiology/clinics/mammography" $(n=3)$, "Anxious patients/dealing with bad news" $(n=2)$, "Not keen on reporting mammograms" $(n=2)$, "Breast surgeons did a lot of their own procedures taking away training from me" $(n=1)$, "Skills mix. Not made to feel like a specialist" $(n=1)$, "Concerns regarding breast screening programme" $(n=1)$, "Limited exposure to acutely unwell patients/limited pathology" (n=2), "MDT (multidisciplinary team)" ( $n=1)$, "There are a few breast consultants who are clearly unhappy in their work" $(n=1)$.

When asked how they felt about the amount of exposure to breast radiology they receive during core training, $78.6 \%$ felt it was "about right", $12.6 \%$ felt it was "not enough", and $8.6 \%$ felt it was "too much" (Fig. 8a). The data were then filtered to assess whether any correlation could be established between these figures and the actual amount of exposure during core training. When the length of the rotation was considered, there appeared to be no appreciable difference between those who felt their exposure to breast radiology was about right, too much, or too little (Fig. 8b). There did, however, appear to be an emerging trend when the number of sessions per week was considered (Fig. 8c). Those who felt they did not have enough 
exposure to breast radiology tended to have two or three sessions per week; those who felt their exposure was about right had three or four sessions per week. For those who felt they had too much exposure, the data were less uniformly distributed, likely due to the small numbers, but the number of sessions per week tended to be higher (Fig. 8c).

When asked whether or not their core breast radiology rotation influenced their decision to do breast radiology, more than half said that they knew they never wanted to train in breast radiology and their rotation did not further influence that decision (Table 5). Approximately one in six respondents said they were not previously considering breast radiology but their rotation changed their mind and made them want to do it. Less positively, approximately one in seven respondents said they may have considered breast radiology but their rotation actually deterred them.

Of the 17 respondents that had said there was no routine core breast radiology rotation on their training scheme, 94\% (15 respondents) said there were other opportunities to gain exposure to breast radiology and $6 \%$ (one respondent) said they did not know whether other opportunities existed. One respondent did not give an answer. Respondents who answered "Yes" were asked to give more information on alternative arrangements. Seven gave free-text answers: "Arranged my own/private rotation" (3); "ad hoc sessions/variable allocated sessions depending on hospital" (3), "Only 1 week of breast radiology attachment as ST1" (1). Of the 16 respondents, seven (44\%) felt they did not receive enough exposure to breast radiology, and the other nine (56\%) felt it was about right.

Finally, trainees were asked to comment on any factors that they felt might help encourage trainees to choose breast radiology. As far as possible these have been collated and grouped into themes (Table 6). The most frequent suggestions were to 
ensure earlier exposure to breast radiology together with a greater depth of exposure. There were also a number of comments expressing concern that it was difficult to combine training in breast radiology with another area of special interest and that links should be maintained with the main radiology department. Also noteworthy were suggestions that trainees should be able to train in symptomatic breast work only in order to give them the opportunity of combining breast radiology with another area of special interest.

\section{DISCUSSION}

The aim of this survey was to ascertain the factors that influence trainees' decisions whether or not to pursue breast radiology and to try and identify ways in which recruitment to breast radiology may be improved in the future. The precise reasons underlying these are inevitably complex, and a survey of this type cannot provide all the answers, but it is intended that the data gathered will give an overview to inform further discussion regarding resolving the current workforce crisis in breast radiology. Almost one in four UK radiology trainees participated in the survey. Overall, all trainee demographics were proportionately represented. Distribution of the survey was dependent on JRF representatives forwarding the link to all trainees in their region/deanery, and although all regions were represented, some regions comprise more than one school; the present data do not enable determination of the response rate from individual schools. There was good representation from each training year, and the male : female ratio of $60: 40$ matches that of UK radiology trainees as a whole. ${ }^{4}$ There was also balanced representation from those who have chosen breast radiology, those who have chosen another special interest, and those who have not yet decided, thereby limiting potential effects of self-selection bias. 
For those who chose further training in breast radiology, the most commonly cited reason was simply having an interest in the subject matter. Conversely, the most commonly cited reasons for not choosing breast radiology in those who had already chosen another specialty interest was that they did not find it interesting, reinforced by "find[ing] it boring". The underlying reasons why people do or do not finding the subject interesting were not explored, and it is therefore unclear to what extent this perception is modifiable. As some of the free-text comments suggested, it is likely that this is a "Marmite" effect: for some it is an area they either "love or hate". Nevertheless, a positive experience during the core rotation was seen as an important influence by those who chose breast radiology. This therefore should represent a window of opportunity for specialists to engage with trainees as much as possible to try and highlight the variety and complexity of modern breast radiology, ensuring broad exposure to all imaging modalities, hands-on experience of interventional techniques, as well as debunking myths such as the nature of the work being monotonous and repetitive. The role of the modern breast radiologist is varied, and the elements that might be perceived as monotonous, such as screen reading, are in reality a relatively small part of the workload once other sessions such as symptomatic clinics, "problem-solving clinics", MDT meetings, guidewire localisation, and MRI are factored into a job plan. Breast radiologists are in the ideal position to reinforce this. Furthermore, breast imaging offers many opportunities for research, quality improvement, and audit, much of which may be collaborative with other members of the MDT. Involving core trainees in such projects at an early stage in their careers will help them boost their portfolios whilst increasing their exposure to breast imaging.

Just over half of respondents who had completed their core rotation said it did nothing to change the notion that they knew they never wanted to train in breast 
radiology; however, the fact that $17 \%$ of respondents said that they were not previously considering breast radiology but their core rotation changed their mind and made them want to do it, shows that a positive experience can make a significant difference. That said, almost as many trainees were put off from choosing breast radiology than had been positively influenced, with almost $14 \%$ being dissuaded by their experience. This should form a salutary lesson for clinical and educational supervisors in the specialty.

One of the challenges of providing a positive experience for trainees during their core training is low staffing and the pressures of service provision risking compromise of teaching time; however, giving time to trainees and showing them the positive aspects of breast radiology could be a valuable investment if it increases uptake into the specialty. Conversely, if trainees are not given the time and support to see the specialty in a positive light, it may dissuade them from pursuing it into advanced training, which will only perpetuate the staffing crisis. Encouragingly, once trainees have chosen breast radiology they are overall happy with the decision, reflecting the importance of getting them on board at the earliest opportunity.

When planning core rotations in breast radiology, it seemed that most trainees felt that a 3 month rotation with 3-4 sessions per week was "about right". It was also a recurring theme that trainees like to maintain links with the main department, as the feeling of being "isolated from main radiology" featured strongly in the reasons for not choosing breast radiology. Indeed, $80 \%$ of those who have chosen breast radiology said they still planned to maintain general interests alongside breast radiology. In many hospitals, the Breast Unit is physically separate from the main radiology department. It is important therefore that clinical and educational supervisors in breast radiology work with training programme directors to ensure that core and higher training rotations offer an appropriate balance and mix of sessions. 
Featuring prominently in the free-text comments in Table 6 was that early exposure to breast radiology may be another way to help develop trainees' interests in the specialty. This is not to suggest that the core rotation need be brought forward, but consideration should be given to organising sessions with trainees as early as ST1, to give an introduction to breast radiology, and importantly, to highlight its many positive factors. Similarly "taster" sessions interspersed as part of other rotations could be a good opportunity to spark interest.

Workforce issues in breast screening are not new and breast imaging has long pioneered skill-mix with increasing the role of non-radiologists such as advanced practitioner radiographers and breast clinicians, and developing the consultant radiographer role. ${ }^{7}$ Although the contribution of these roles to providing services is recognised and valued, this should not detract from the need to increase the number of breast radiologists to lead and develop breast services, as well as the need to address the critical shortage of academic breast radiologists. ${ }^{5}$ Concerns were also expressed by a number of survey respondents regarding the perceived threat to the specialty and training opportunities through advancing roles of radiographers. These are feelings that should be taken into consideration when trying to attract trainees into breast radiology. Crucially, however, recruitment to these wider roles is fraught with its own difficulties, and they each face similar attrition rates to breast radiologists; a quarter of the workforce across each of the three roles is expected to retire in the next 5 years, with almost half retiring over the next 10 years. ${ }^{5}$

In conclusion, there has never been a greater need to recruit specialty trainees into breast radiology. The future of the specialty lies in hands of current radiologists and urgent action is required to ensure the sustainability of breast services and drive further improvements to patient care. The findings from this 
survey should act as a starting point to developing strategies to try and improve recruitment. Moreover, these results should be regarded as a challenge to all breast radiologists to engage with trainees from an early stage in their training and to enthuse them with the many positive aspects of a career in breast radiology.

\section{ACKNOWLEDGEMENTS}

The authors thank the British Society of Breast Radiology Executive Committee for their input and for providing financial support for the survey prizes. S.L. was funded by a National Institute for Health Research Clinical Lectureship. R.S. is supported with research funding from the National Institute for Health Research Cambridge Biomedical Research Centre.

\section{REFERENCES}

1. Cancer Research UK. Breast cancer statistics. Available at: http://www.cancerresearchuk.org/health-professional/cancer-statistics/statistics-bycancer-type/breast-cancer (Accessed 8/10/2016)

2. National Cancer Intelligence Network. Cancer e-Atlas. Available at: http://www.ncin.org.uk/cancer information tools/eatlas/ (Accessed 8/10/2016)

3. Willett AM, Michell MJ, Lee MJR (Eds). Best Practice Diagnostic Guidelines for Patients Presenting with Breast Symptoms, 2010. Available at: http://www.associationofbreastsurgery.org.uk/media/4585/best practice diagnostic guidelines for patients presenting with breast symptoms.pdf

(Accessed $8 / 10 / 2016)$

4. The Royal College of Radiologists. Clinical Radiology UK workforce census report. London: The Royal College of Radiologists, 2015. 
5. British Society of Breast Radiology, NHS England, Public Health England, and The Royal College of Radiologists. The breast imaging and diagnostic workforce in the United Kingdom: results of a survey of NHS Breast Screening Programme units and radiology departments. London: The Royal College of Radiologists, 2016.

6. The Royal College of Radiologists. Specialty training curriculum for Clinical Radiology. Available at: http://www.rcr.ac.uk/sites/default/files/clinical radiology curriculum 2015.pdf (Accessed 8/10/2016).

7. NHS Breast Screening Programme National radiographic workforce survey 2016.

NHS. Available at: https://www.gov.uk/government/publications/breast-screeningnational-radiographic-workforce-report-2016. Accessed ????

Figure 1. Percentage of respondents by stage of training. One respondent selected "Other", a post-CCT trainee.

Figure 2. Trainees who have chosen breast radiology as their area of special interest: reasons why they chose it.

Figure 3. Trainees who have chosen breast radiology as their area of special interest: how they feel about their decision.

Figure 4. Trainees who have already chosen a special interest other than breast radiology: factors about breast radiology that influenced their decision not to choose it. 
Figure 5. Trainees who have not yet made their decision regarding a special interest: factors/perceptions they see as positive about breast radiology.

Figure 6. Trainees who have not yet made their decision regarding a special interest: factors/perceptions they may have for not choosing breast radiology.

Figure 7. (a) Years in which core breast radiology rotations take place. (b) Length of core breast radiology rotations, $15 \%$ selected "Other", stating various rotation lengths ranging from 1 to 6 weeks. (c) Number of sessions per week allocated to breast radiology during the core rotation.

Figure 8. (a) How trainees feel about the amount of exposure they receive to breast radiology during core training. (b) Correlation with the length of rotation. (c) Correlation with the number of sessions per week.

Table 1. Number of respondents per training region.

Deanery

North West London: Imperial, Chelsea \& Westminster, Northwick Park

North Central \& East London: Royal Free, St Barts \& the Royal London, University College Hospital 17

South London: Guy's \& St Thomas', King's College, St George's

East of England: Cambridge, Essex \& Bedfordshire, Norwich

East Midlands: Leicester, Nottingham

North West: Mersey

North West: Manchester

North East: Newcastle upon Tyne, Teesside

Northern Ireland MDTA: Northern Ireland

Thames Valley: Oxford

Scotland (East): East Scotland (Dundee)

Scotland (North): North Scotland (Aberdeen)

Scotland (South East): South East Scotland (Edinburgh)

Scotland (West): West Scotland (Glasgow)

South West (Severn): Bristol

South West (Peninsula): Plymouth \& Peninsula

Wales: South Wales, North Wales

Wessex: Portsmouth, Southampton

West Midlands: North Staffordshire (Stoke on Trent), West Midlands (Birmingham)

Yorkshire \& the Humber: Leeds/Bradford, Hull \& East Yorkshire, Sheffield 


\begin{tabular}{lll} 
& $n$ & $\%$ \\
\hline Gender & & \\
Male & 164 & 59.6 \\
Female & 109 & 39.6 \\
Prefer not to say & 2 & 0.7 \\
Age group (years) & & \\
$25-29$ & 87 & 31.6 \\
$30-34$ & 120 & 43.6 \\
$35-39$ & 59 & 21.5 \\
$40-44$ & 5 & 1.8 \\
$45-49$ & 2 & 0.7 \\
$50+$ & 0 & 0 \\
Prefer not to say & 2 & 0.7 \\
\hline
\end{tabular}

The total number of respondents was 275 .

Table 3. Factors contributing to trainees' enjoyment of their core breast rotation

\begin{tabular}{lll} 
& \multicolumn{2}{l}{ Respondents } \\
\cline { 2 - 3 } Reason & $n$ & $\%$ \\
\hline Made to feel welcome by staff in the department & 117 & 77.5 \\
Good support from the consultants & 114 & 75.5 \\
Lots of procedures/intervention & 97 & 64.2 \\
Encouraged to get involved with procedures & 89 & 58.9 \\
Enjoyed the patient contact & 87 & 57.6 \\
Good support from the radiographers & 54 & 35.8 \\
Good exposure to the different modalities & 46 & 30.5 \\
Found the subject matter interesting & 37 & 24.5 \\
Good opportunities for audit or research & 19 & 12.6 \\
There was nothing I enjoyed about the rotation & 6 & 4.0 \\
Other (please specify) & 2 & 1.3 \\
\hline The total number
\end{tabular}

The total number of respondents answering the question was 151, but respondents

were able to select more than one reason.

Table 4. Factors contributing to trainees' dislike of their core breast rotation

\begin{tabular}{lll} 
Reason & \multicolumn{2}{l}{ Respondents } \\
\cline { 2 - 2 } There was nothing I disliked about & 61 & 40.4 \\
$\quad$ the rotation & 36 & 23.8 \\
I find the subject matter boring & 22 & 14.6 \\
$\begin{array}{l}\text { Other (please specify) } \\
\text { Not given many opportunities to }\end{array}$ & 21 & 13.9 \\
$\quad \begin{array}{l}\text { carry out procedures } \\
\quad \text { different modalities used }\end{array}$ & 17 & 11.3 \\
in breast radiology & &
\end{tabular}




$\begin{array}{lcc}\text { Too much patient contact } & \text { ACCEPTED } & \text { MANUSCRIPT } \\ \text { Made to feel that my needs were } & 16 & 10.6 \\ \text { less of a priority than } & 13 & 8.6 \\ \text { other trainees (e.g. more senior STs or radiographers) } & \\ \text { Too many procedures/intervention } & 7 & 4.6 \\ \text { Did not feel welcome } & 2 & 1.3 \\ \text { Lack of support from the radiographers } & 2 & 1.3 \\ \text { Lack of support from consultants } & 1 & 0.7 \\ \text { Poor opportunities for audit or research } & 0 & 0.0\end{array}$

The total number of respondents answering the question was 151, but respondents were able to select more than one reason.

Table 5 Did your core breast radiology rotation(s) influence your decision to do breast radiology?

\begin{tabular}{lll} 
Reason & \multicolumn{2}{l}{ Respondents } \\
\cline { 2 - 3 } & $n$ & $\%$ \\
\hline $\begin{array}{l}\text { No I knew I never wanted to train in breast and it did } \\
\text { nothing to influence that decision }\end{array}$ & 82 & 54.3 \\
$\begin{array}{l}\text { Yes I wasn't previously considering breast radiology but } \\
\text { it changed my mind and made me want to do it }\end{array}$ & 26 & 17.2 \\
$\begin{array}{l}\text { Yes I may have considered breast radiology but my rotation } \\
\text { deterred me from choosing it as a subspecialty }\end{array}$ & 21 & 13.9 \\
$\begin{array}{l}\text { Yes I had been considering it before my rotation and it } \\
\text { helped me make up my mind to pursue it }\end{array}$ & 17 & 11.3 \\
$\begin{array}{l}\text { No I already wanted to do it and my rotation did not } \\
\text { influence that decision }\end{array}$ & 3 & 2.0 \\
$\begin{array}{l}\text { No My rotation took place after I was required to make } \\
\text { my decision regarding subspecialty training }\end{array}$ & 2 & 1.3 \\
Total & &
\end{tabular}

Table 6 Are there any factors you feel might help encourage trainees to train in breast radiology?

'SELLING' BREAST RADIOLOGY AS AN ATTRACTIVE AREA OF SPECIAL INTEREST

Good work-life balance/quality of life (6)

Lots of jobs (2)

Private working opportunities (2)

Good level of practical procedures/intervention (3)

Good patient interaction/own clinics (3)

Offer better pay scale/financial incentives (2)

Little/no on-call, non-emergency routine work (2)

"Breast radiologists need to sell the specialty to trainees and make it seem interesting" 
"Talks/teaching to junior trainees from senior trainees interested in breast/breast consultants on the merits of breast radiology."

"Very secure as everything is double reported"

"The consultants work very closely together, so there is always support"

"Perhaps workforce planning could highlight areas where there will be consultant posts to trainees starting in radiology...the stats of where the jobs will be might open minds"/More knowledge of career opportunities (2)

POSITIVE TRAINEE EXPERIENCES AND EXPOSURE TO BREAST RADIOLOGY DURING TRAINING:

Early exposure to the specialty/clinics during training (16)

More exposure to the specialty/clinics/intervention (13)

Exposure during medical school (2)

Being made to feel welcome with good support/encouragement from the breast consultants during the core rotation (4)

Provide a positive experience in core training (1)

Provide more teaching/one-to-one teaching (4)

Mentor opportunity (1)

Increase awareness of other techniques used in breast radiology (including MRI) to avoid limited perceptions (2)

More trainee involvement during the attachment in all aspects of the specialty, including "hands-on experience" of procedures and MDT meetings (5)

Having a rotation in ST3 (2): "I think that if I had done the rotation in ST3 I would have been more confident with biopsies and done more of them. If I had been undecided it may have swung the balance in favour of a career in breast radiology."

"Requires more supervised dedicated screening time - it takes a trainee time to get into the art of looking at screening mammos - they are not easy!"

"Being in a department with a structured approach to level 1 training is very helpful in enabling trainees make an informed decision about breast radiology"

"The thing I enjoyed most about my breast rotation was how friendly, relaxed and supportive everyone was - this atmosphere is vital to entice trainees to do breast radiology [...] also, focus needs to be put on the positives of doing breast radiology - the holistic approach [...] the recent exciting advances in breast imaging/intervention [...] and of course the very flexible nature of the specialty which allows for part time working and focusing on other areas such as management."

SYMPTOMATIC VERSUS SCREENING WORK

More opportunities to do just symptomatic breast work leaving time to do another subspecialty (4)

Exposure to both symptomatic and screening (2).

MAINTAINING LINKS WITH MAIN DEPARTMENT \& COMBINING BREAST RADIOLOGY WITH GENERAL RADIOLOGY/OTHER SPECIAL INTEREST AREAS

Allow training with another subspecialty (concerns that breast consultants are too busy to do anything else) (7)

Not to become too excluded/isolated from general radiology/more integration with rest of the department (3)

ADDRESSING THE NEGATIVE ASPECTS \& THREATS TO BREAST RADIOLOGY

"Stop outsourcing breast radiology to other specialties and professions."

"The specialty feels very service driven. As a result, consultants are under time pressure and cannot test or show us interesting cases."

LOVE IT OR HATE IT

"Breast radiology is quite a niche subspecialty which most people seem to either love or hate."

"I think it is either something you enjoy or it isn't, the rotation was very well supported, it just wasn't for me."

Where possible, similar responses have been collated; numbers in parentheses refer

to the number of respondents making that comment. Direct quotes appear in

quotation marks; some of these have been edited for brevity or correction of

typographical errors. 


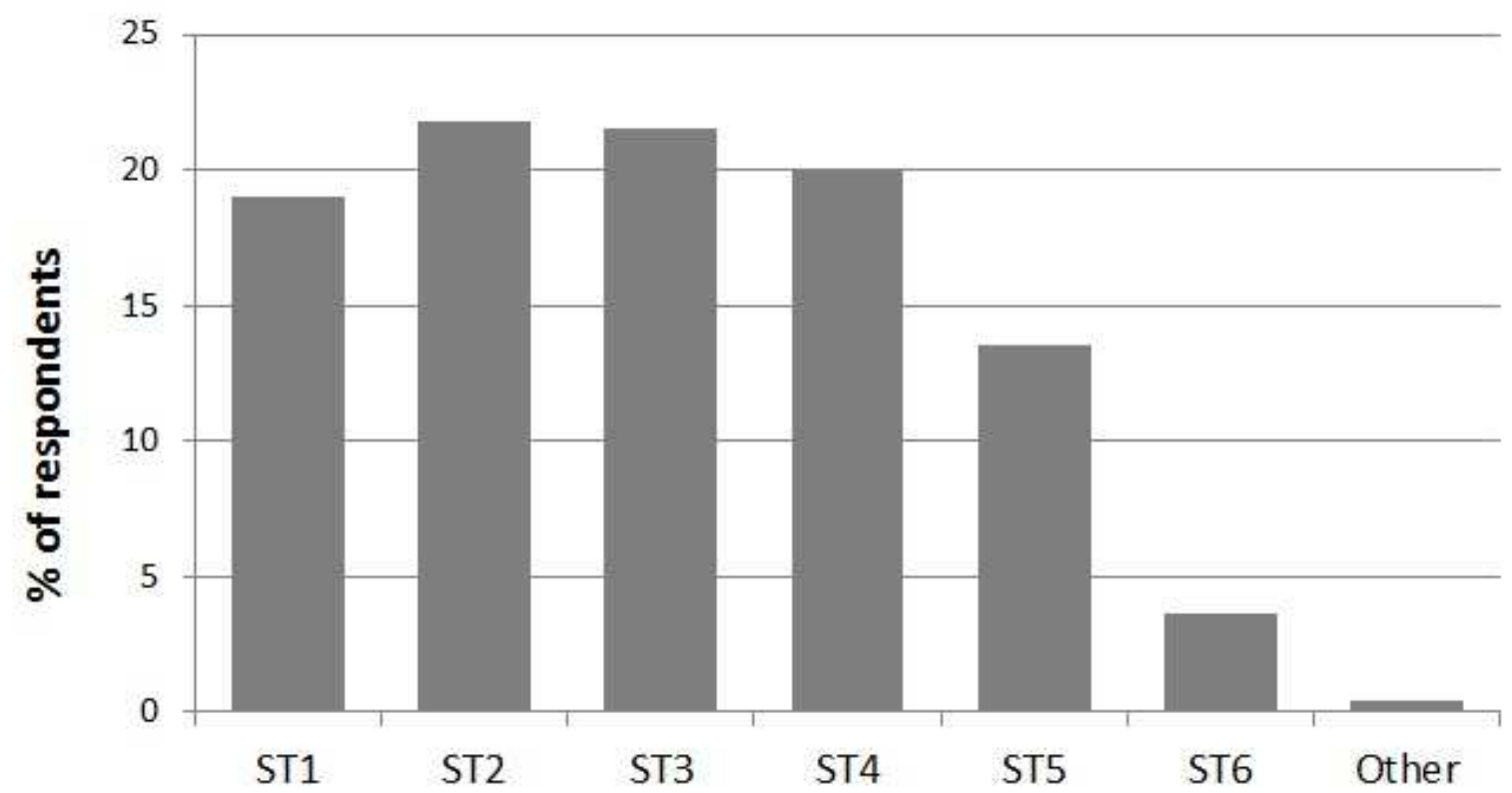




\section{Interested in the subject \\ Good level of patient contact}

Positive experience during core training rotation

Feel breast radiologists make a positive difference to patient care

Good job opportunities

Lots of procedures/intervention

Supportive environment

Positive role models

Enjoy working within multidisciplinary team

Encouraged by consultant breast radiologists to subspecialise in breast

Offers good work/life balance

Wide range of imaging modalities

Little threat of being outsourced

Flexible working hours

Opportunity for less than full time working

No or limited on call

Good opportunities for research/audit

Opportunity to pursue pure breast radiology without having to do general or other subspecialty

Opportunities for private practice or extra paid sessions

Other (please specify)
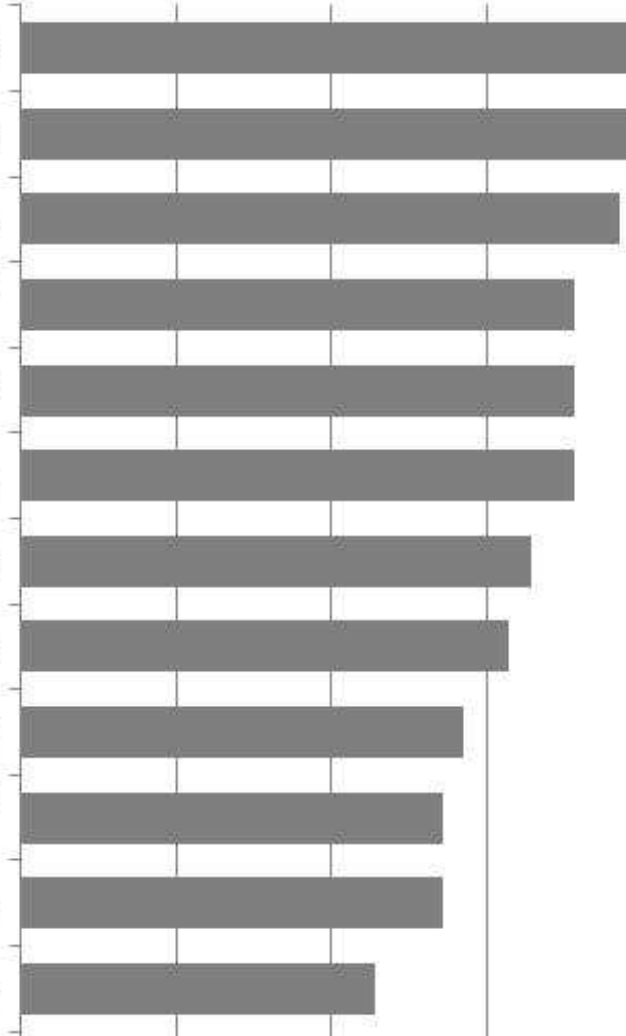

$-$
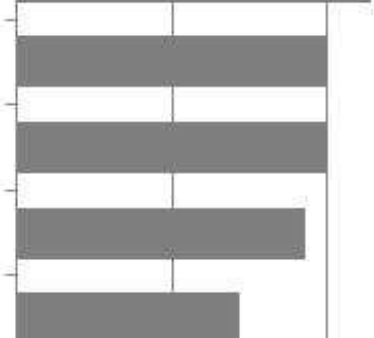

$-$

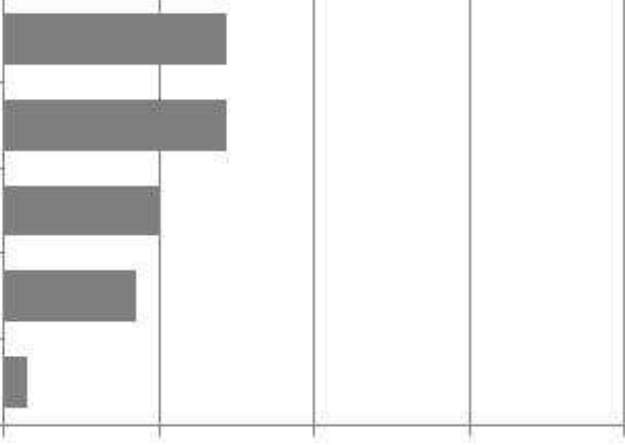

0 


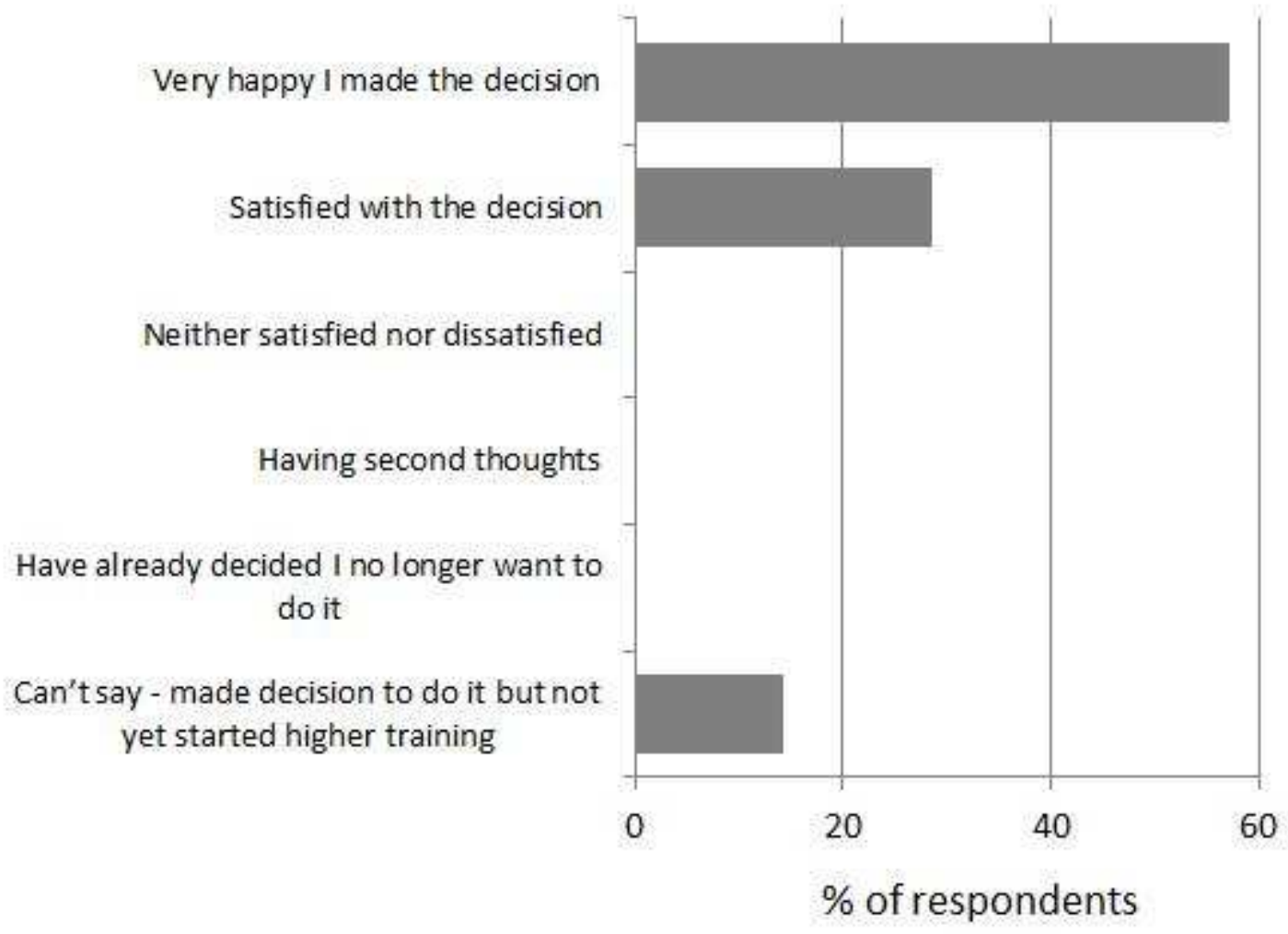




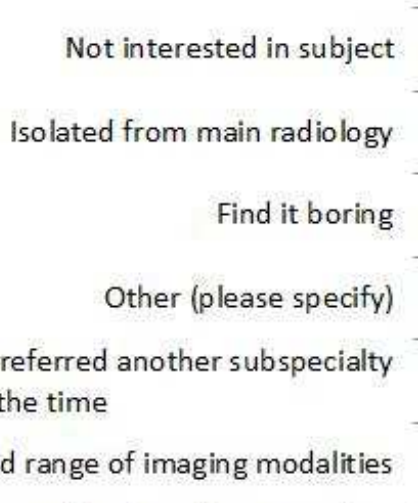

Adequate exposure at core training level but enough to put me off

Too much patient contact

Inadequate exposure at core training level to help make decision

Concerned about the potential for litigation

Feel role threatened by advancing role of radiographers

Concerned about satisfying quality as surance mechanisms

Concerned about the future of breast radiology as a subspecialty

Lack of role model

Too much intervention/biopsies

Limited opportunity for private practice/extra paid sessions

Not enough intervention/biopsies

Negative attitude of breast radiologists regarding their own specialty

Subspecialty has negative profile among other radiologists (non-breast)

Not enough opportunities for research/audit Concerned about job opportunities

Lack of opportunity to undertake a fellowship in the UK

Negative profile in the media
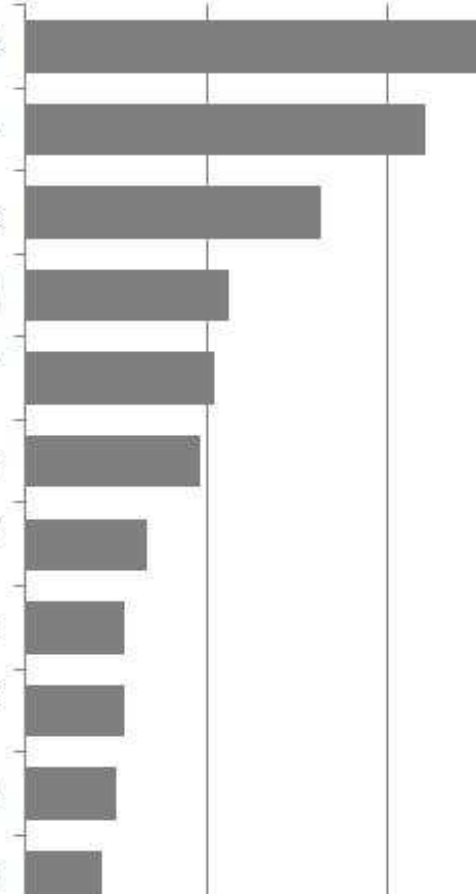

$-$
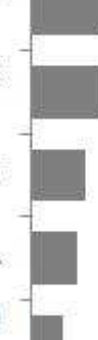
Good level of patient contact

Lots of procedures/intervention

Enjoy working within multidisciplinary team

Good job opportunities

Offers good work/life balance

No or limited on call

Flexible working hours

Opportunity forless than full time working

Feel breast radiologists make a positive difference to patient care

Little threat of being outsourced

Positive role models

Good opportunities for research/audit

Encouraged by consultant bre ast radiologists to subspecialise in breast

I have not given breast radiology any consideration and have no specific views

Supportive environment

Positive experience during core training rotation

I find it an interesting subject area

Opportunities for private practice or extra paid sessions

Wide range of imaging modalities

Opportunity to pursue pure breast radiology without having to do general or other ra diology subspecialty

Other (please specify)

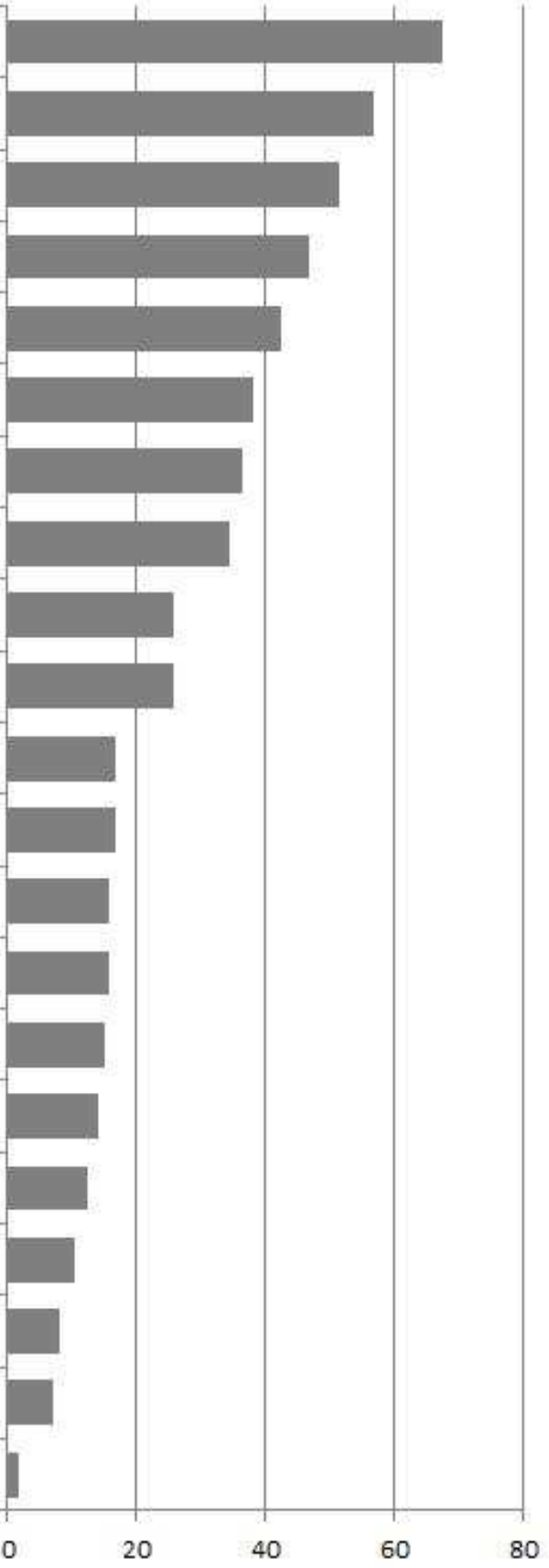

$\%$ of respondents 


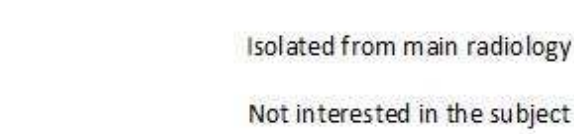

Concerned about the potential for litigation

Find it appealing but I prefer another subspecialty

Inadequate exposure at core training level to help make decision

I have not given breast radiology any consideration and have no specific views

Find it boring

Subspecialty has negative profile among other radiologists (nonbreast)

Concerned about the future of breast radiology as a subspecialty

Other (please specify)

Feel role threatened by advancing role of radiographers

Limited range of imaging modalities

Concerned about satisfying quality assurance mechanisms

Limited opportunity for private practice/extra paid sessions

Lack of role model

Adequate exposure at core training level but enough to put me off

Concerned about job opportunities

Too much patient contact

Negative attitude of breast radiologists regarding their own specialty

Too much intervention/biopsies

Lack of opportunity to undertake a fellowship in the UK

Not enough intervention/biopsies

Not enough opportunities for research/audit

Negative profile in the media

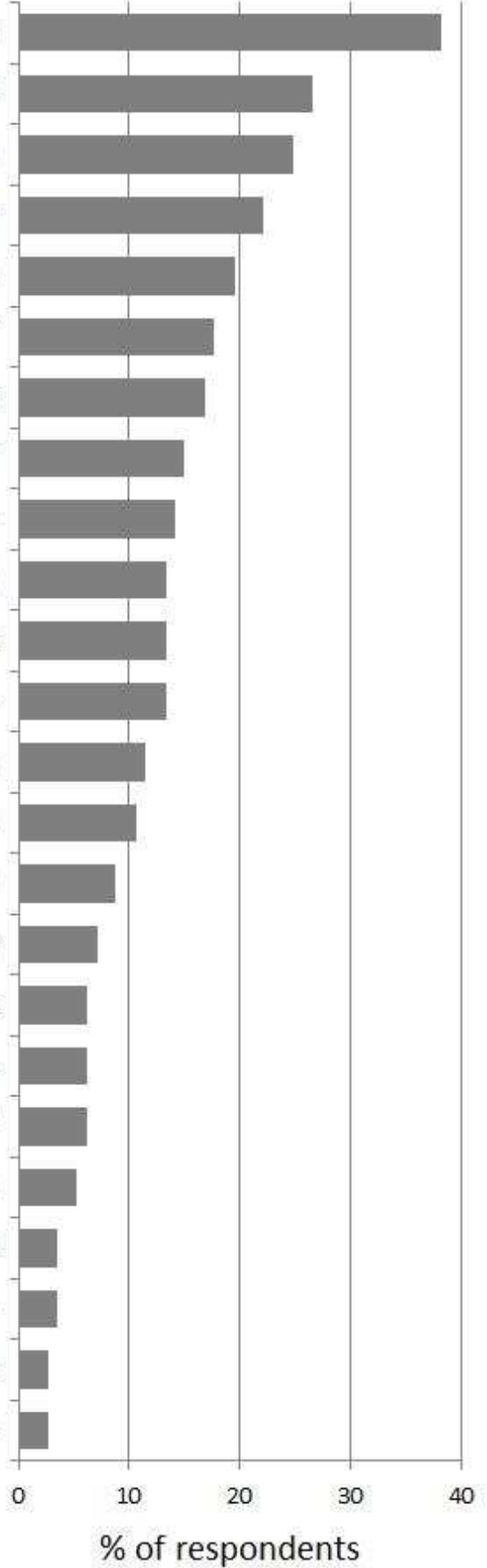


(a)

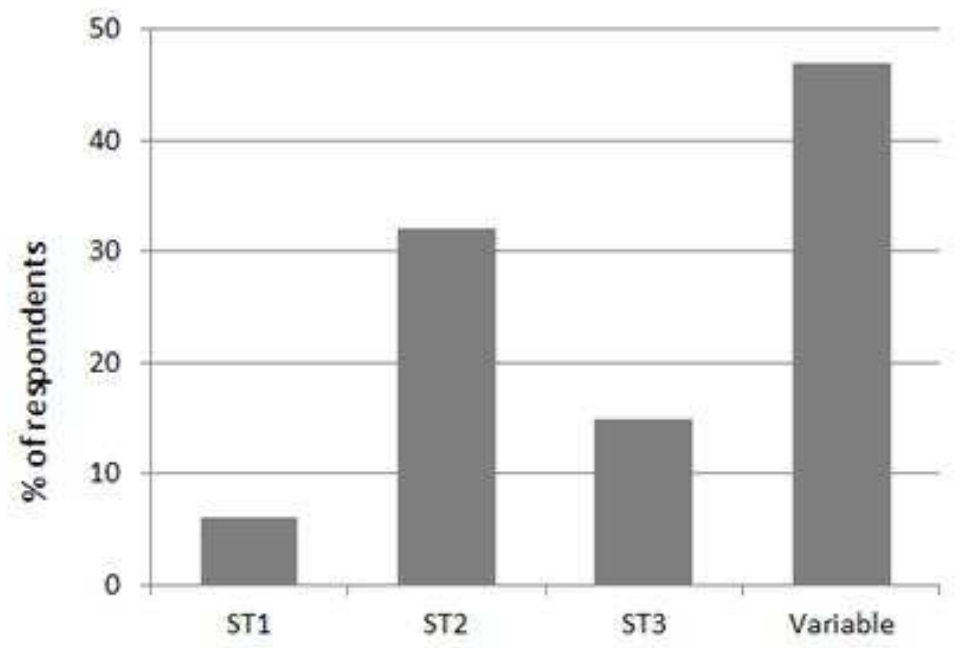

Year of core breast radiology rotation

(b)

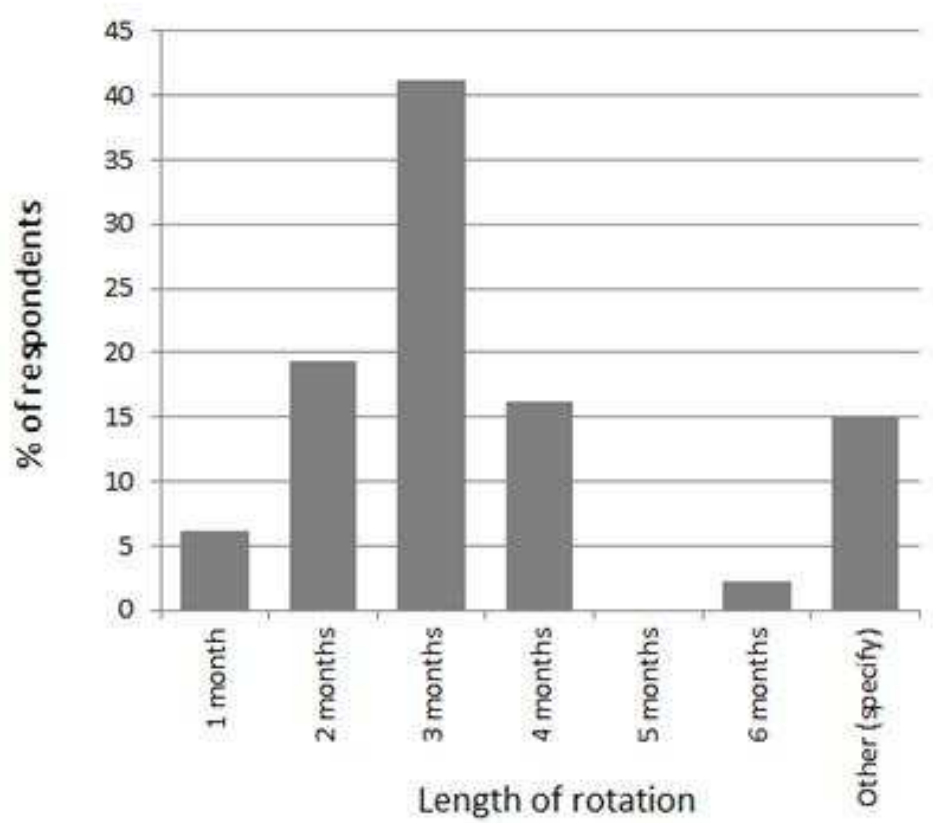

(c)

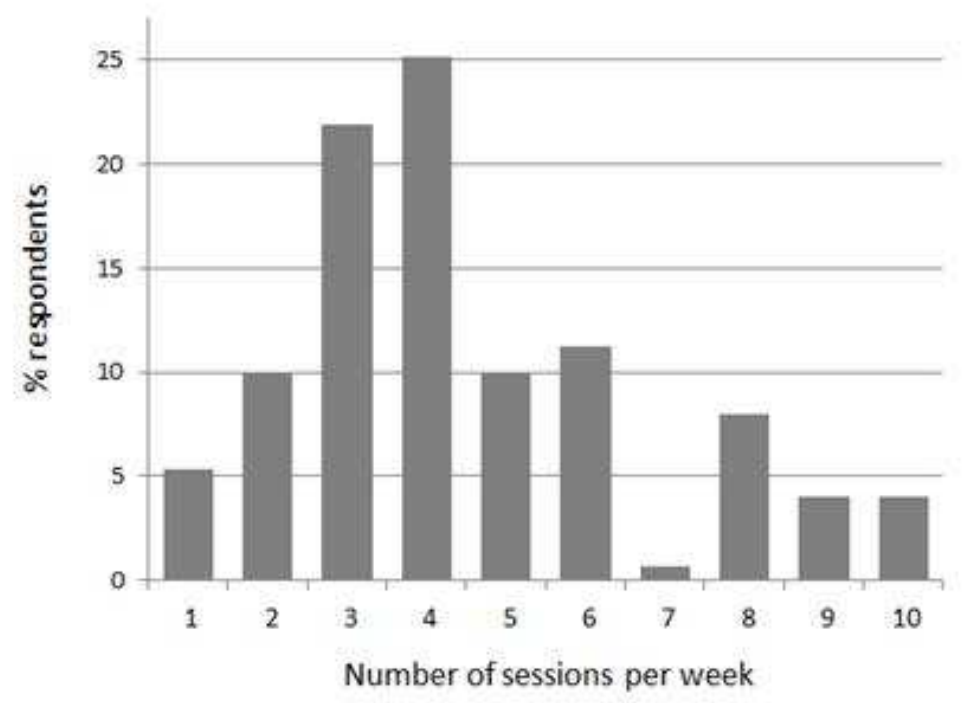




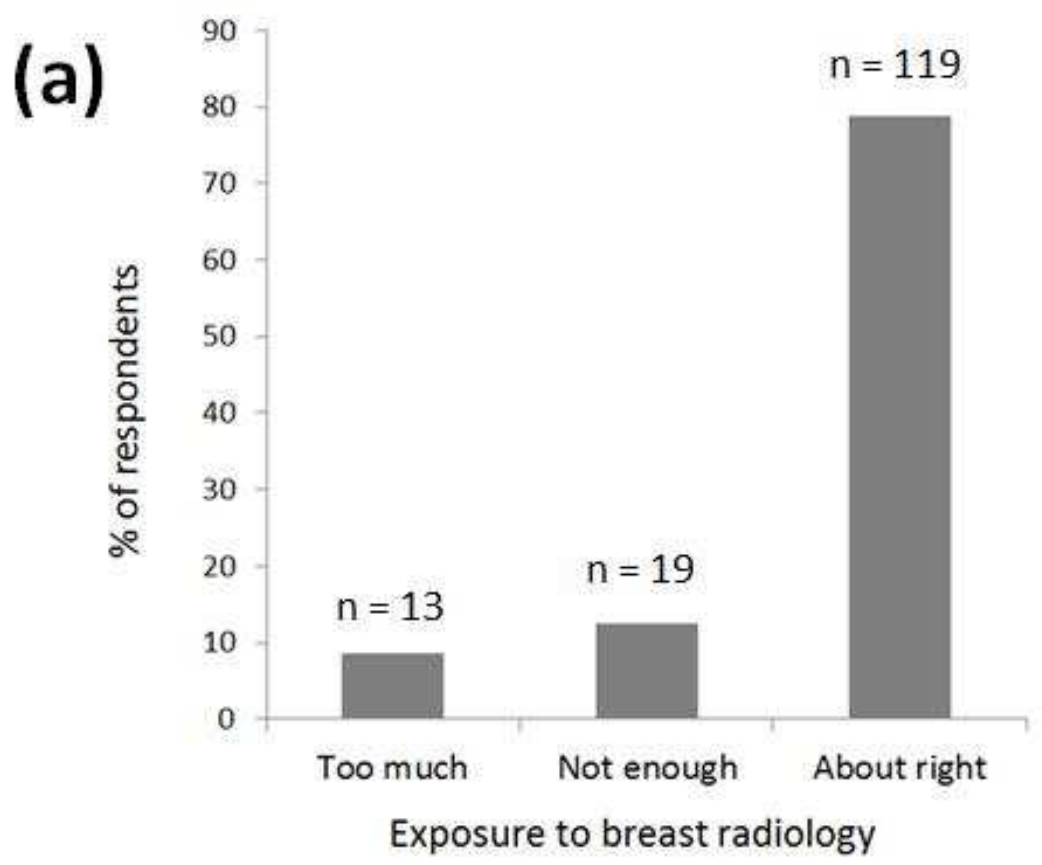

(b)

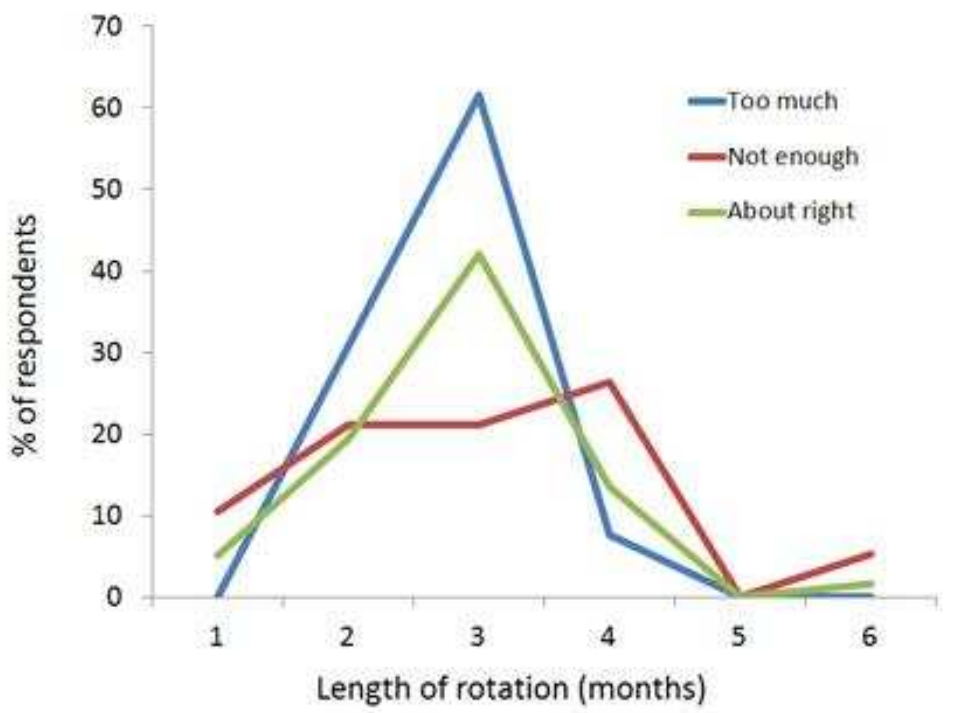

(c)

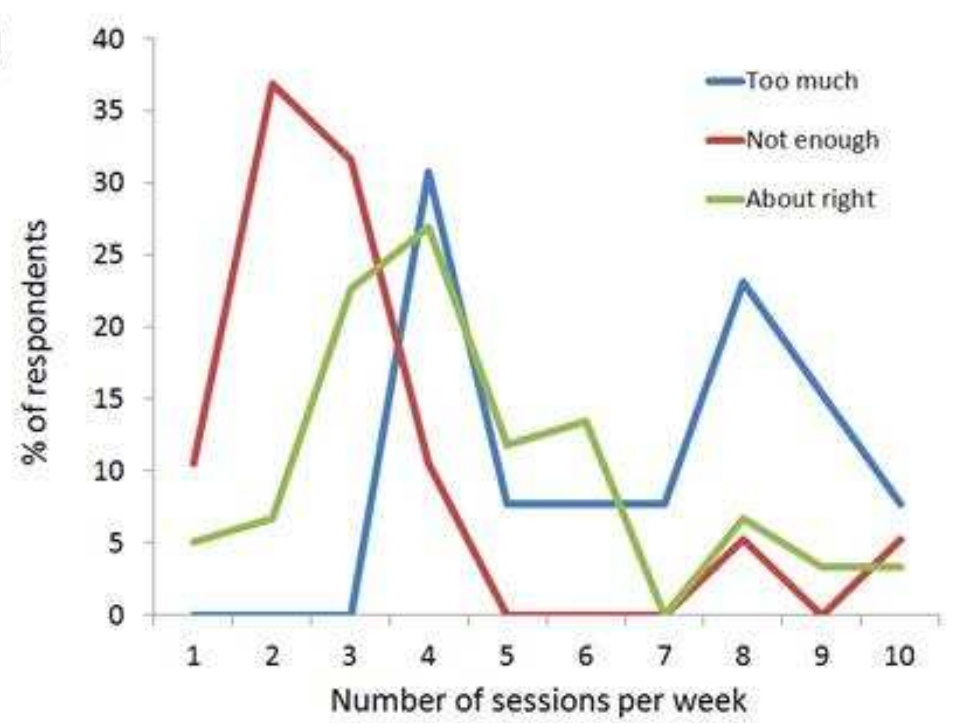




\section{Highlights}

- Core training experience in breast radiology influences trainees' choice of advanced training.

- Positive aspects of breast radiology include level of patient contact and interventional procedures.

- Negative aspects include isolation from general radiology and finding the subject matter boring.

- Breast radiologists are encouraged to engage positively with trainees from an early stage. 


\section{Author contributions}

Simon Lowes: 1 guarantor of integrity of the entire study, 2 study concepts and design, 3 literature research, 5 experimental studies / data analysis, 6 statistical analysis, 7 manuscript preparation, 8 manuscript editing

Megan Bydder: 2 study concepts and design, 7 manuscript preparation, 8 manuscript editing

Ruchi Sinnatamby: 2 study concepts and design, 3 literature research, 7 manuscript preparation, 8 manuscript editing 